\title{
202 Production of Fine Metallic Powders By Hybrid Atomization Process
}

\author{
Kazumi Minagawa, Tunzhong Liu, Hideki Kakisawa, Kohmei Halada
}

Ecomaterials Center, National Institute for Materials Science, 1-2-1 Sengen, Tsukuba City, Ibaraki 305-0047, JAPAN

\begin{abstract}
Hybrid Atomization is a new developed powder making process that hybridizes free fall gas atomization with centrifugal atomization well. This technique can produce very fine, spherical powders with mean diameters around ten micrometers and high yields economically. Its concept and basic principles were discussed. Process experiments were carried out and the optimal processing conditions obtained. Results show that the influences of processing parameters and optimum conditions are very different from those in conventional atomization processes. A new correlation of atomization equation applicable to hybrid atomization is proposed and discussed.
\end{abstract}

\section{Key Words: Fine Powders; Hybrid Atomization}

\section{INTRODUCTION}

Very fine metal powders, with diameters around $10 \mu \mathrm{m}$ or less, often exhibit unique structures or properties that are not attainable in large size ranges [1]. Demand for such powders is increasing rapidly as new technologies emerge which can make use of their unique characteristics [2]. Some of these rapidly growing applications are metal injection molding, electronic solders, conductive inks, etc. However, the requirements for powder characteristics in these applications are very strict and conventional atomization techniques cannot meet them economically. In an attempt to overcome such a bottleneck, a new powder-making process , Hybrid Atomization, has been developed recently to produce very fine metal powders with high quality and low production cost [2].

\section{CONCEPT AND BASIC PRINCIPLES}

The new idea is to control the film formation on disk in order to facilitate production of fine powders. In centrifugal atomization, the powder sizes are usually very coarse even under very high rotating speeds. The main reason for it was found to be the formation of a thick liquid film on the rotating disk before melt breakup. The thicker the film is, the coarser the mean particle size becomes.
Meanwhile, the more instable the flow type of film is, the wider the powder size distribution will be. If the film formation on disk can be controlled well to obtain a very thin but stable film, finer powders with tighter size distribution should be produced. However, it will be difficult or impractical to do so only by adjusting processing parameters in conventional centrifugal atomization because much higher rotating speed or very low liquid supply rate will be. So a new way should be paved to control the film formation effectively and economically.

The basic concept is to hybridize free fall gas atomization with centrifugal atomization. In our work, low pressure gas atomization was utilized to promote the formation of a very thin stable film before centrifugal breakup and give a better preparation for the final pulverization of melts. According to our theoretical analysis, the liquid film thickness in hybrid atomization is about $50 \sim 60 \%$ as that in corresponding centrifugal atomization. In most cases of hybrid atomization, the basic flow type of liquid flow on disk is laminar flow and more stable than that in conventional centrifugal atomization. ince the melt has been dispersed by gas spray before its final atomization, it should be easier to be broken down into finer particles under the centrifugal force. 


\section{PROCESS AND EXPERIMENTAL}

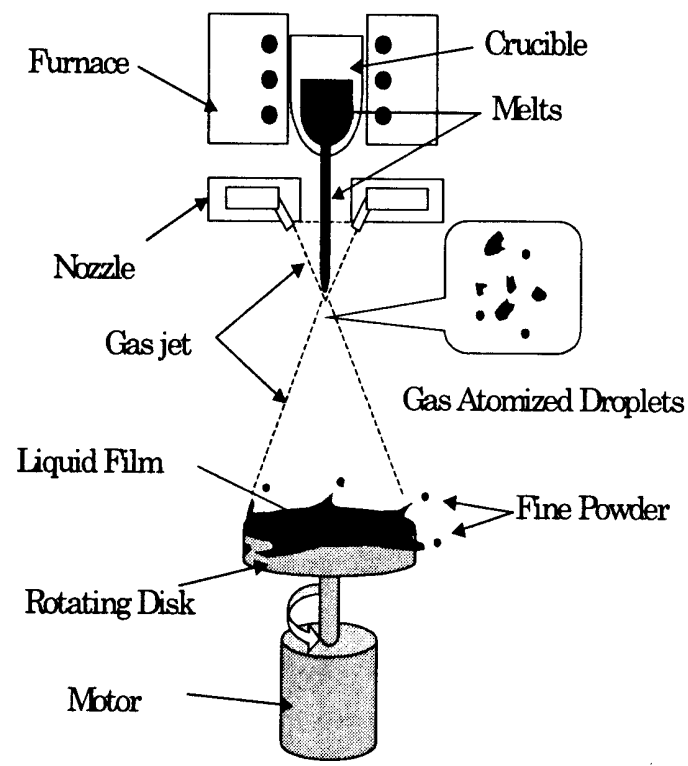

Fig.1 Schematic diagram of hybrid atomization device

A schematic diagram of hybrid atomization free fall gas atomizer into coarse liquid droplets. These droplets are sprayed onto a high-speed rotating disk and form a thin liquid film on disk. Then this film is pulverized by centrifugal force. The solidified powders are collected by a vacuum cleaner at the bottom of atomization chamber.

Our preliminary experiments showed that its main processing parameters are metal superheat, disk speed, spray distance and melt diameter. Other parameters such as gas pressure and melt diameter were found to have no remarkable influence on the powder characteristics. Hybrid atomization was carried out for $\mathrm{Sn}-9 \mathrm{wt} \% \mathrm{Zn}$ with the variation range of the main parameters as follows: melt superheat $573 \mathrm{~K} \sim 823 \mathrm{~K}$; disk rate $5000 \sim 30000 \mathrm{rpm}$; spray distance $50 \sim 160 \mathrm{~mm}$; disk diameter $50 \sim 100 \mathrm{~mm}$. Other constant parameters were: gas pressure $0.6 \mathrm{MPa}$ (Nitrogen), gas atomization angle $2 \pi / 9 \mathrm{rad}\left(40^{\circ}\right)$ and melt diameter $2 \mathrm{~mm}$. The disk is made by SIALON. The powder size and size distribution were measured by the methods of Sieving and Coulter Counter. The shape and microstructure of powders were observed by JSL5400 (SEM) and OM.

\section{RESULTS AND DISCUSSION}

\subsection{Powder characteristics}

As shown in Fig. 2 and Table 1, hybrid atomization can produce finer spherical powders with a higher yield and a narrower size distribution than gas atomization. For comparison, in hybrid atomization the yields of powder fraction under $26 \mu \mathrm{m}$ is $82 \% \sim 90 \%$. But in conventional gas atomization it is lower than $10 \%$ under the same conditions. If the gas atomizer works only, the powders obtained have an average particle size $64 \mu \mathrm{m}$ with the geometric standard deviation about 2.0. If the rotating disk runs only, the average particle size is $80 \sim 140 \mu \mathrm{m}$ with the geometric standard deviation 1.3 1.5. In case of operating the whole device of hybrid atomization, the

Table 1 Comparison among atomization methods

\begin{tabular}{|c|c|c|c|}
\hline Method & $\begin{array}{c}\text { Powder } \\
\text { Size }(\mu \mathrm{m})\end{array}$ & $\begin{array}{c}\text { Size } \\
\text { Distribution }\end{array}$ & $\begin{array}{c}\text { Powder } \\
\text { Shape }\end{array}$ \\
\hline GA & $20 \sim 100$ & $\begin{array}{c}\text { Log-Normal } \\
\sigma \mathrm{g}: 2.0 \pm 0.3\end{array}$ & $\begin{array}{c}\text { good } \\
\text { sphere }\end{array}$ \\
\hline $\mathrm{CA}$ & $25 \sim 85$ & $\begin{array}{c}\text { tight } \\
\mathrm{g}: 1.3 \sim 1.5\end{array}$ & sphere \\
\hline WA & $5 \sim 150$ & $\begin{array}{c}\text { broad } \\
\sigma_{\mathrm{g}: 1.7 \sim 2.4}\end{array}$ & irregular \\
\hline $\mathrm{HA}$ & $10 \sim 15$ & $\begin{array}{c}\text { tight } \\
\sigma_{\mathrm{g}: 1.7 \sim 2.4}\end{array}$ & sphere \\
\hline
\end{tabular}

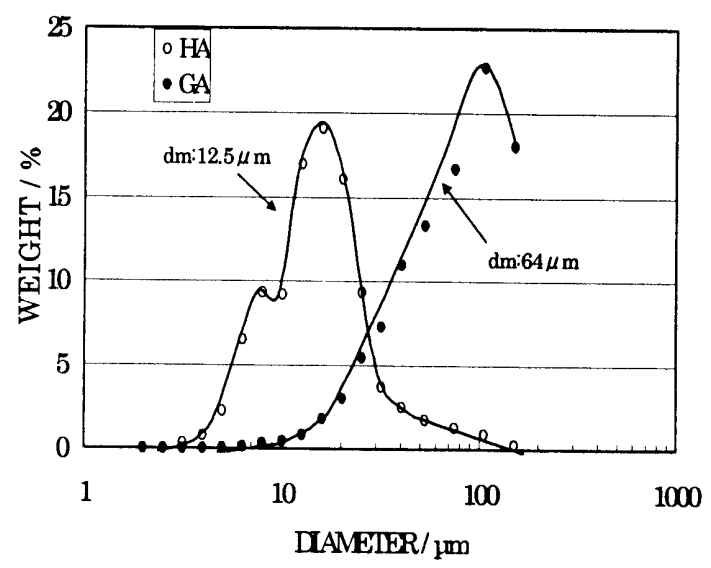

Fig.2 Comparison of results between hybrid atomization and gas atomization 


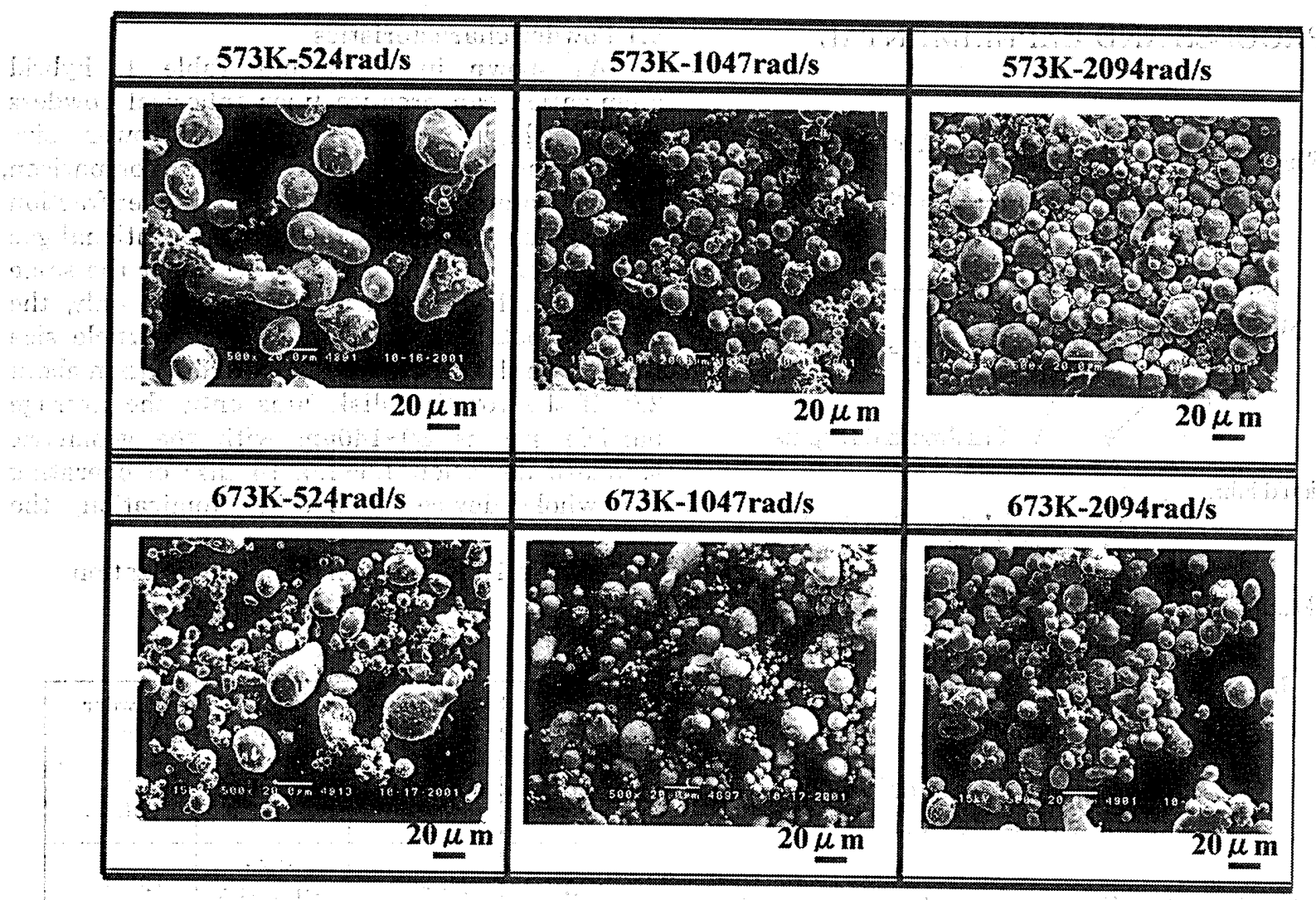

Fig.3 Powder characteristics of hybrid atomization under different conditions

average powder size can decrease to $10 \sim 15 \mu \mathrm{m}$ with the corresponding geometric standard deviation only $1.3 \sim 1.7$.

As shown in Fig.3, most of powder particles have a spherical or nearly spherical shape. Few powders have the shape of dumb-bell or granule. In addition, few satellites are found around main particles under typical hybrid atomization conditions.

\subsection{Influences of Processing Variables}

4.2.1 Melt temperature. According to Fig.4, when melts are atomized at a low temperature under low disk rate, the mean powders are coarse with two peaks in their size distribution. When the melt superheat increases to a moderate temperature $(673 \mathrm{~K})$, powders become finer and the minor peak in its size distribution curve shifts to the finer particle range. However, if melt temperature is too high (823K), this trend of powder refinement with increasing superheat will not be kept. On the contrary, the average powder size and geometric standard deviation increase. Also as shown in Fig.3, the higher the superheat is, the better the spherical shape of powders becomes. In addition, it seems that a proper superheat can reduce satellites around main particles.

4.2.2 Disk rate and size. As shown in Fig.5, when disk rate increases from 5000 rpm to $20000 \mathrm{rpm}$, the mean powder diameter decreases and the size distribution changes from one peak to two peaks. Also in Fig.5, when disk diameter increases from $50 \mathrm{~mm}$ to $100 \mathrm{~mm}$, the curve of powder size distribution changes from two peaks into almost one sharp peak. Compared with those of other parameters, the influences of disk speed (including disk rate and size) are quite remarkable on both powder size and size distribution.

4.2.3 Spray distance. As shown in Fig.6, when spray distance increases from $50 \mathrm{~mm}$ to $100 \mathrm{~mm}$, 


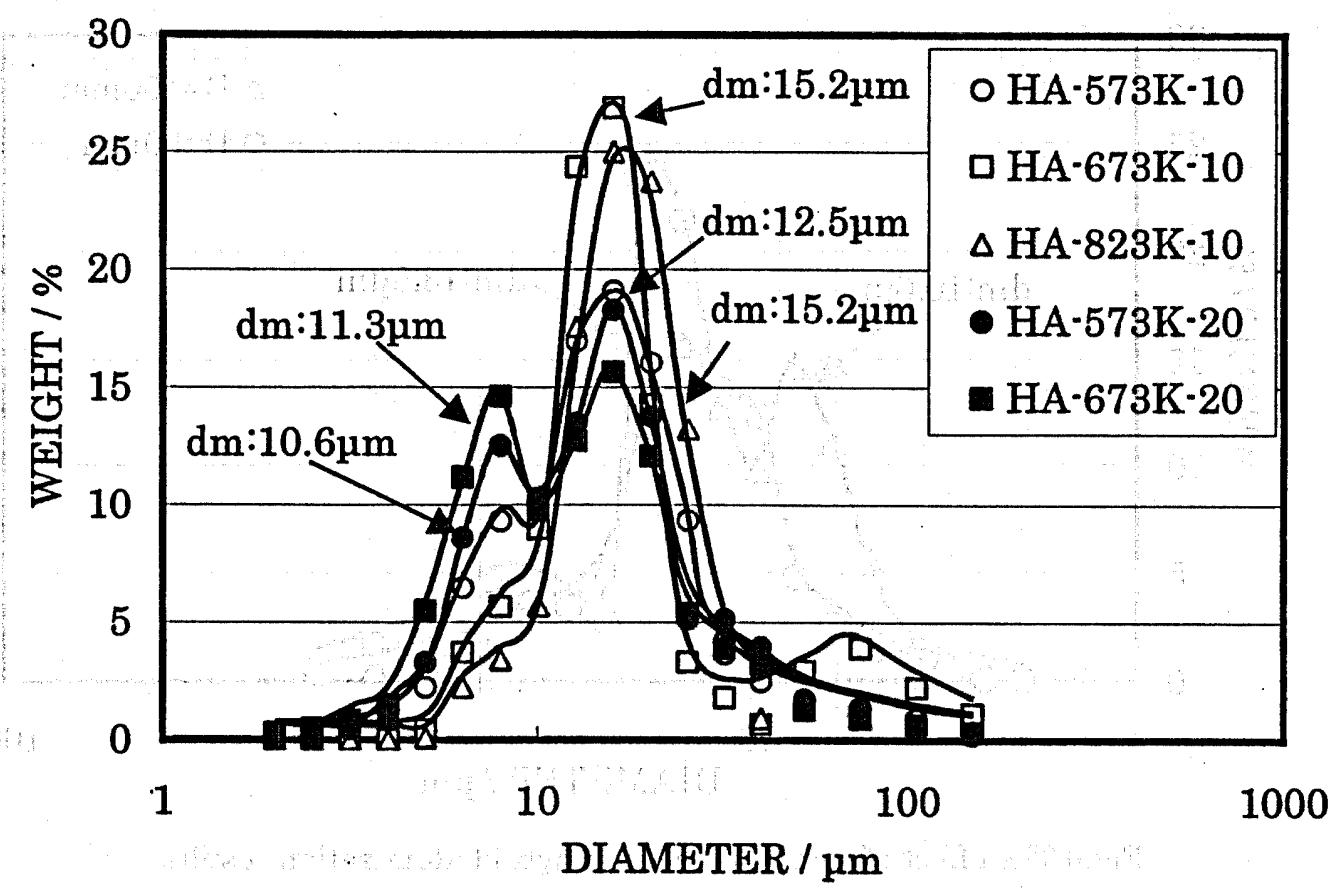

Fig.4 The influence of superheat on hybrid atomization results

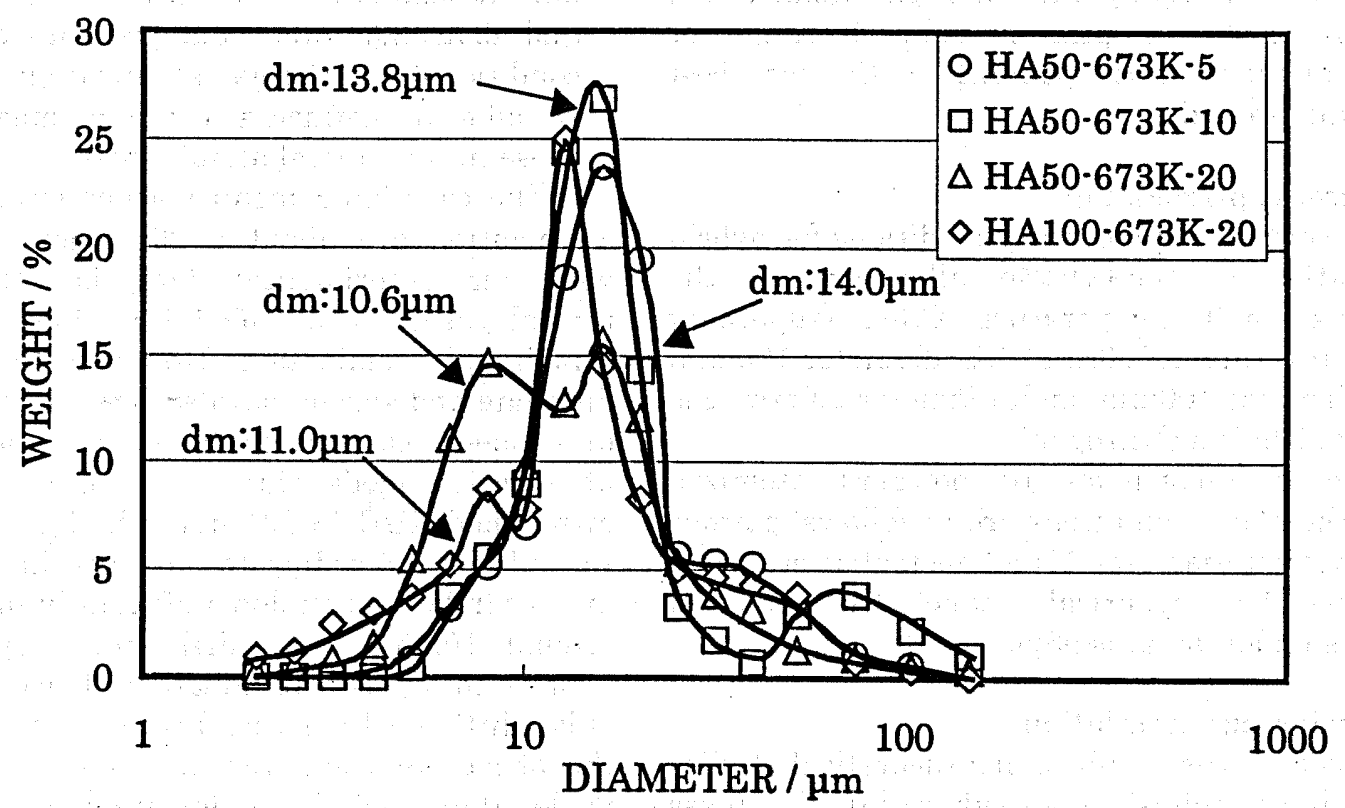

Fig.5 The effects of disk rate and size on hybrid atomization results

the powders obtained becomes finer and size distribution tighter. However, according to our previous work [3], if spray distance continues to increase from $100 \mathrm{~mm}$ to $160 \mathrm{~mm}$, powders become coarse again. In addition, when the spray distance is too small $(50 \mathrm{~mm})$, a lot of deposit was found to 


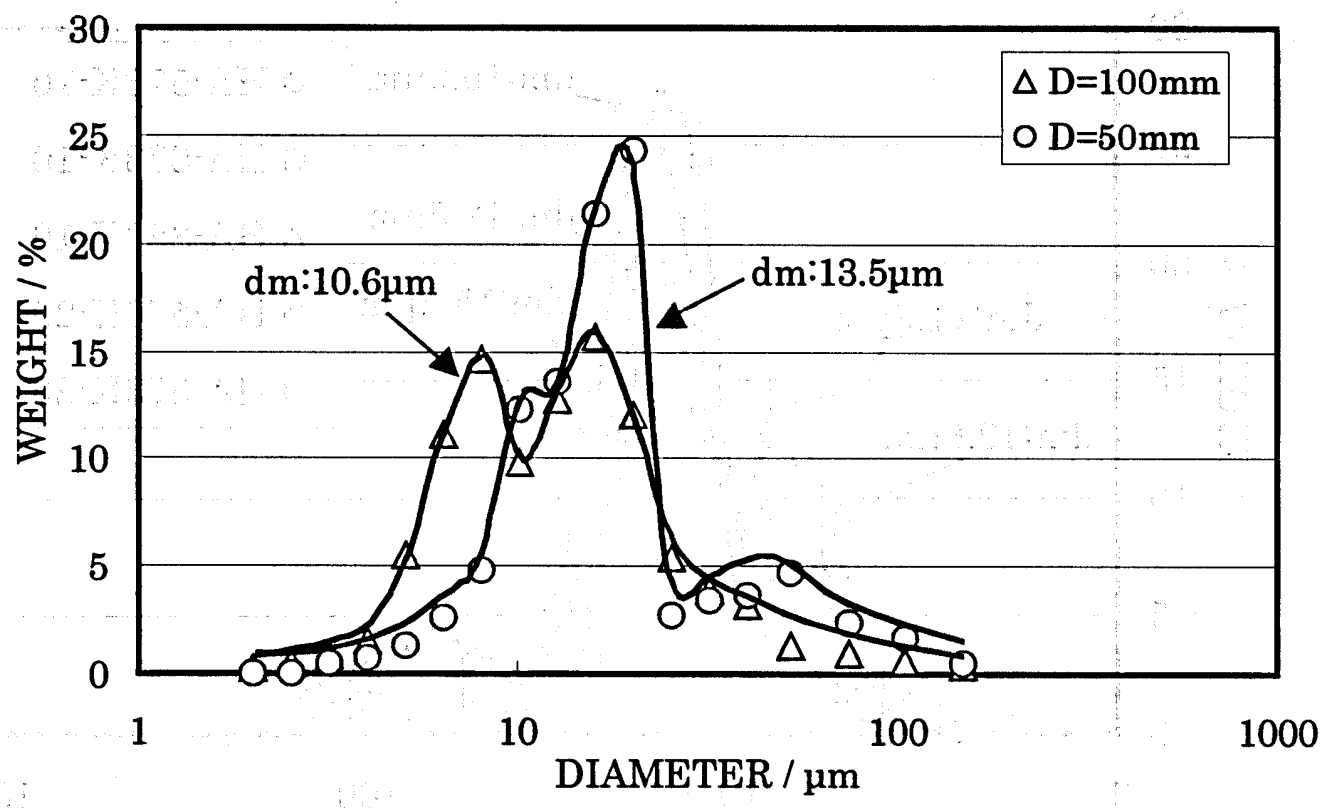

Fig.6 The effect of spray distance on hybrid atomization results

solidify on the rotating disk. However, if the spray distance is too large, many droplets will not be atomized centrifugally after their gas atomization. So there exists an optimum value or range for spray distance corresponding with the best atomization results.

\subsection{Process optimization}

The optimum processing conditions for hybrid atomization of $\mathrm{Sn} \cdot 9 \mathrm{wt} \% \mathrm{Zn}$ alloy are as the following: melt temperature $673 \mathrm{~K}$ (superheat $200 \mathrm{~K}$ ); disk rate $20000 \mathrm{rpm}$; disk diameter $100 \mathrm{~mm}$; spray distance $100 \mathrm{~mm}$; melt diameter $2.0 \mathrm{~mm}$; gas pressure $0.6 \mathrm{MPa}$ (Nitrogen).

The characteristics of powders atomized under the above conditions are as follows: powder mass median diameter $11 \mu \mathrm{m}$; geometric standard deviation 1.3; spherical shape; the yield of powders under $45 \mu \mathrm{m}$ is $98 \%$.

\subsection{Powder size correlation}

Based on the result of our theoretical studies that will be published elsewhere [4], the mass median diameter of powders in hybrid atomization obeys the following correlation.

$\mathrm{d}_{\mathrm{m}}=3.25\left(\mathrm{P} / \mathrm{P}_{0}\right)^{-1 / 2}[1+\mathrm{K} \sin (\theta / 2)]^{1 / 2} *\left(\frac{\sigma}{\rho D \omega^{2}}\right)^{1 / 2}$
Where $d_{m}$ is the mass median diameter of powders; $\mathrm{P}$ and $\mathrm{P}_{0}$ are the pressure of gas jet and atmosphere $\left(\mathrm{P}_{0} \cong 0.1 \mathrm{MPa}\right) ; \mathrm{K}$ is a constant and about 23.4 under our present experimental conditions; $\theta$ is the gas atomization angle; $\sigma, \rho$, $D$ and $\omega$ are defined as the same meanings with those in centrifugal atomization.

The calculated mean powder sizes in hybrid atomization are about $8 \sim 20 \mu \mathrm{m}$ and agree well with our experimental data, i.e. $10 \sim 15 \mu \mathrm{m}$ in typical cases. It is $1 / 6 \sim 1 / 8$ as fine as that in centrifugal atomization. However, the effects of disk rate and size on powder size reduce when the disk speed is very high. This is because the atomization mode shifts from DDF mode to a mixed mode (DDF + LF) under high disk speed [5]. In addition, according to our experiment results, melts can be broken down efficiently into droplets around $10 \mu \mathrm{m}$ at the disk linear speed about $100 \mathrm{~m} / \mathrm{s}$ in hybrid atomization. Powders become only a little bit finer with higher disk speed. Since the above equation was deduced from the DDF mode, there will be a deviation between mean powder size prediction and actual atomization results with very high rotating speeds.

\section{DISCUSSION}

In hybrid atomization, the main role of gas atomization is to produce a very thinner and more 
stable liquid film on disk before its final breakup. Gas atomization provides a proper spray dispersion of melt, enhances the liquid flow on disk and increases the stability of liquid film flow [5]. In centrifugal atomization the flow type of liquid film depends on specific conditions and sometimes belongs to turbulent flow [6]. But under most of typical hybrid atomization conditions it should be laminar flow since its Reynolds number based on surface flow is much smaller than that in centrifugal atomization.

On the other hand, in hybrid atomization several main processing parameters show different influences on atomization results from those in conventional atomization processes. Among them, disk rate and size have very remarkable effects on powder size and size distribution. This is because disk speed affects not only the liquid formation on disk but also the atomization mode. When the disk linear velocity increases, the breakup ability of centrifugal atomizer becomes stronger. The liquid film becomes thinner and its main disintegration mode tends to be the DDF+LF or even LF mode. Thus powders obtained become finer. As for the powder size distribution, it depends heavily on the stability of liquid film and atomization procedure. The more stable the liquid film and final centrifugal breakup procedure, the tighter the powder size distribution. In addition, both melt superheat and spray height are also two important factors. They influence the characteristics of liquid film on disk firstly and then the droplet formation because the melt thermo-physical properties such as surface tension, viscosity and density relate closely to its temperature variation. Anyway, it is known that the temperature dependence of surface tension and viscosity should not be pronounced for metals and alloys [7]. If enough superheat and proper spray height can be adopted to avoid the premature solidification of melt before its final pulverization, the hybrid atomization results will not change much with further variation of either melt temperature or spray height. So the optimal conditions should be a good combination between enough superheat and proper spray height. However, since powders are formed by centrifugal force in hybrid atomization and their characteristics are mainly controlled by final breakup, the parameters such as gas pressure, gas atomization angle and melt diameter, which govern atomization results in gas atomization, affects the final results only indirectly in hybrid atomization. Thus their influences are just minor in this new process and far less pronounced than those in conventional gas atomization.

\section{CONCLUSIONS}

(1) A new process, Hybrid Atomization was developed to hybridize free fall gas atomization with centrifugal atomization well. This technique can produce very fine powders with high yields and low costs.

(2) The influences of several main processing parameters on atomization results are different from those in conventional atomization processes.

(3) Under the optimal conditions, spherical Sn-9wt\%Zn powders can be produced with mean diameter $11 \mu \mathrm{m}$, standard deviation 1.3, yields under $26 \mu \mathrm{m}$ about $90 \%$ and under $45 \mu \mathrm{m}$ over $\mathbf{9 8 \%}$.

(4) A new atomization equation applicable to hybrid atomization was presented and agrees with experimental data well.

\section{REFERENCES}

[1] Ayers J. D., Anderson I. E., Very Fine Metal Powders, Journal of Metals, 8, (1985), p16

[2] Minagawa K., Liu Y., Kakisawa H., Halada K., Fine Powder Production by Hybrid Atomization, Abstracts of Autumn Meeting of Japan Society of Powder and Powder Metallurgy, 3-25A, (2001), p84

[3] Minagawa K., Production of Fine Powders By A Process Composed of Gas Atomization And Centrifugal Atomization, Proc. Of Autumn Meeting of Japan Metals Society, Tohoku University, 9, (1997), p128

[4] Liu Y., Minagawa K., Kakisawa H., Halada K., Process Optimization And Atomization Mechanism of Hybrid Atomization, The 2002 World Congress on Powder Metallurgy and Particulate Materials, Orlando, U.S., (2002), June. [5] Liu Y., Minagawa K., Process Optimization And Atomization Mode of Hybrid Atomization, International Journal of Powder Metallurgy, (2002), (Submitted)

[6] Halada K., Suga H., Theoretical Investigation of Centrifugal Atomization Parameters, Powder and Powder Metallurgy (in Japanese), 37(4), (1990), P492

[7] Smithells G. M., Metals Reference Book, Fifth Edition, Butterworths, London, UK, (1976) 